\title{
Evaluation of choroidal thickness in children with type 1 diabetes: the role of optical coherence tomography in diabetic retinopathy screening
}

\author{
Basak Can Ermerak ${ }^{1}$, Ozgur Yalcinbayir ${ }^{2}$, Erdal Eren ${ }^{3}$, Elif Sobu ${ }^{3}$, Cansu Erseven$^{2}$, and Ahmet Ali Yucel ${ }^{2}$ \\ ${ }^{1}$ University Hospitals Cleveland Medical Center, Department of Ophthalmology, Rainbow's Babies and Children \\ Hospital, Division of Pediatric Ophthalmology, Ohio, U. S. A. \\ ${ }^{2}$ Uludag University School of Medicine, Department of Ophthalmology, Bursa, Turkey \\ ${ }^{3}$ Uludag University School of Medicine, Division of Pediatric Endocrinology, Bursa, Turkey
}

\begin{abstract}
The present study aimed to evaluate choroidal changes and alternations within the structure of the retina prior to visible morphologic signs of diabetic retinopathy (DR) in pediatric type 1 diabetes (T1D) cases. Two hundred and six eyes of 103 pediatric patients with T1D without DR and 88 eyes of 44 healthy controls were enrolled. They underwent a comprehensive ophthalmic examination and optical coherence tomography evaluation. Choroidal thickness (ChT) measurements were performed manually on macular and peripapillary regions. There was no significant difference between the two groups in terms of age, intraocular pressure, and axial length ( $p>0.05)$. ChT measurements of subfoveal, nasal, and temporal macula were slightly thinner in the diabetic group, and no statistical significance was found ( $p$ $=0.835, p=0.305$, and $p=0.054$, respectively). Peripapillary ChT of eight sectors were also thinner in T1D; however, superonasal, nasal, inferonasal, and inferior sector values were significantly different $(p=0.010, p=0.020, p=0.019$, and $p=0.018$, respectively). In conclusion; this study demonstrated evidence of peripapillary choroidal thinning in pediatric diabetic patients without visible signs of retinopathy.
\end{abstract}

Key words: choroidal thickness, diabetes, diabetic retinopathy, optical coherence tomography

\section{Introduction}

Diabetic retinopathy (DR) is a leading vascular complication of type 1 diabetes (T1D) and an evident cause of acquired blindness among working-age adults (1). The prevalence of retinopathy declined in the pediatric population to approximately $12 \%$ as intense insulin treatment regimens became available (2). Although clinically evident DR is rarely seen during childhood, it is well established that relevant signs may develop during early ages and escalate during puberty. Once diagnosed, these advance cases may constitute significant management challenges for ophthalmologists and endocrinologists. In a bid to minimize complications, it would be crucial to detect preclinical alterations of this disease prior to morphologic changes, particularly given the long life span of these children.

Even though retinopathy is classified as a microvascular complication of diabetes; recent evidence shows that retinal neuronal degeneration in fact precedes the vascular damage $(3,4)$. Retinal ganglion cells are neurons within the retina and their axons form the most inner layer of the retina, called retinal nerve fiber layer (RNFL), which would later become the optic nerve and subsequently extend to the central nervous system. The neuroretinal changes occurring during diabetes include ganglion cell loss, thinning of inner retinal layers, neural apoptosis and glial reactivation $(3,5,6)$. Another aspect to retinal neural degeneration is that vascular supply for inner retinal layers is derived from retinal circulation whereas outer retinal layers are supplied by more oxygenized choroidal circulation. Given this hypoxic state, retinal inner layers may also be more prone to stress due diabetic changes (4). Likewise, the choroid has been also speculated to have an important role in DR pathophysiology. The choroid is a complicated vascular structure which is the main blood supply for outer retinal layers and neurosensorial retina at the foveal avascular

Received: July 2, 2020 Accepted: September 5, 2020

Corresponding author: Basak Can Ermerak, M.D., University Hospitals Cleveland Medical Center, Division of Ophthalmology, Rainbow's Babies and Children Hospital, Division of Pediatric Ophthalmology, 11100 Euclid Ave Ste 1200, Cleveland, OH 44106, U. S. A.

E-mail: dr.basakcan@gmail.com

This is an open-access article distributed under the terms of the Creative Commons Attribution NonCommercial No Derivatives (by-nc-nd) License <http://creativecommons.org/licenses/by-nc-nd/4.0/>. 
zone. It also plays a vital role in the metabolism of retinal pigment epithelium (RPE) and photoreceptor function (7). Choroidal vascular degeneration, microaneurysm formation within the choroid, "drop-out" of the choriocapillaris, and choroidal neovascularization have been described among the features of choroidal alterations in diabetic retinopathy (8-10).

A thorough fundus examination by an experienced eye care provider remains the gold standard for screening and diagnoses of diabetic retinopathy. However, the advent of imaging technologies has opened the way for other cost-effective and efficient options including retinal fundus photography and optical coherence tomography (OCT) to enhance DR diagnoses at outpatient diabetes clinic settings (11). OCT is a high resolution, noninvasive imaging technique that employs near-infrared light to create cross-sectional images of tissues. In ophthalmology, this technology provides the ability to visualize the retinal architecture in a layer by layer manner and obtain in-vivo quantitative assessments of these retinal segments; in fact, leading to the term of "optical biopsy" (12). Furthermore, it is now possible to get in-vivo quantitative measures of ganglion cells and RNFL thickness in just minutes during a clinic visit via this device. Enhanced depth imaging (EDI) is a recent addition to OCT technology that provides good resolution even in deeper tissues. For instance, until recently, it was almost impossible to visualize the structure of the choroid in a non-invasive manner due to its location between the inner, densely pigmented RPE, and the outer opaque sclera. However, since the introduction of EDI-OCT, the visibility and segmentation of the choroid have been widely improved.

A better clinical understanding of alterations within the structure of the retina and choroid may help to examine pre-clinical pathophysiology of neurovascular conditions. As the previous attempts have been made to identify such changes, there is still a lack a biomarker for the early diagnosis of DR. This context has led many researchers to employ non-invasive imaging technologies to this area. Accordingly, T1D may be considered as another convenient neurovascular model to study these mentioned features in the pediatric population $(3,4)$. To date, choroidal and retinal changes during childhood remain open areas to investigate and advanced OCT technologies may provide insights in this timeframe. Therefore, this study aimed to investigate microstructural and quantitative assessments of the choroid and retina in this subgroup of pediatric cases.

\section{Subjects and Methods}

This retrospective, cross-sectional study included 103 consecutive patients with T1D who had been followed by the Pediatric Endocrinology Department, Uludag University School of Medicine and referred to the Ophthalmology Department at the same institution for an ophthalmologic evaluation, between January 2015 and April 2017. The control group was recruited from our database, and included 44 otherwise healthy, age-matched children who were examined for routine ophthalmic evaluations such as for refractive errors. Local ethics committee approval was obtained and the study complied with the tenets of Declaration of Helsinki.

All patients with T1D enrolled in the study group were between the ages of 7 and 18 years, without visible signs of diabetic retinopathy and had been followedup for at least 1 yr at the Pediatric Endocrinology Department of the same tertiary referral hospital. Exclusion criteria included the following; history of previous ocular surgery; retinal vascular diseases and coexistent ocular disease such as glaucoma; cataract or anterior segment opacifications that may preclude the view; spherical equivalent refractive error of $\geq \pm$ 4.0 diopters; and relatively low visual acuity $(\leq 0.63)$. Moreover, patients with additional chronic diseases other than T1D; such as autoimmune thyroiditis, systemic hypertension, renal dysfunction, hyperlipidemia, or obesity were also excluded to minimize secondary retinal vascular alternations. Among these patients, the ones who had undergone spectral domain OCT (Heidelberg Spectralis; Heidelberg Engineering GmbH; Heidelberg, Germany) imagining, were selected for our study.

The demographic data of age, race, and gender were recorded for each patient. All subjects received a comprehensive ophthalmic examination with determination of best corrected visual acuity (BCVA) by the standard Early Treatment Diabetic Retinopathy Study (ETDRS) chart, intraocular pressure (IOP) with the Goldmann applanation tonometer, slit lamp biomicroscopic anterior segment evaluation, dilated fundus examination via 78D fundus lens and color fundus photography. For each eye, subjective spherical equivalent (SE) refractive error and axial length (AL) (IOLMaster; Carl Zeiss Meditec, Jena, Germany) values were noted. Moreover, charts of systemic evaluation regarding disease duration, hemoglobin A1c (HbA1c) values, treatment modalities, and additional systemic complications were reviewed for each patient.

All subjects underwent retinal and choroidal evaluation via OCT imagining records. Special attention was paid for imagining to be performed during morning hours to avoid the influence of diurnal variations in choroidal thickness and systemic blood pressure values were recorded from the same visit (7). In addition, fundus photographs of each diabetic patient who was referred for evaluation were taken for documentation purposes. The photographs of included subjects were evaluated by two masked retina specialists (Yalcinbayir O, Yucel AA) and confirmed for no detectable signs of diabetic retinopathy.

Choroidal thickness (ChT) measurements were performed manually by using Heidelberg Eye Explorer software. The quality of OCT images was adjusted to be optimal and when necessary, contrast assays were altered to obtain improved images of the choroidal layer. The perpendicular distance between the hyperreflective line at the base of the retina pigment epithelium layer and the hyporeflective line in the choroid-scleral 
interface was defined as the ChT. The OCT images were assessed independently by two masked ophthalmologists (Can B, Yalcinbayir O) and the average of these two values were taken into consideration. A horizontal imaging section extending through the center of the fovea was selected for further analysis with regards to macular ChT measurements and these consisted of three points; subfoveal, 1,500 $\mu \mathrm{m}$ nasal and 1,500 $\mu \mathrm{m}$ temporal intervals from the subfoveal point, as illustrated in Fig. 1. The peripapillary area was defined as an annulus around the optic disc and peripapillary scans were performed by the standard protocol for RNFL assessment using a 360 degrees, 3.4-mm diameter circle centered at the optic disc. Peripapillary ChT was measured at eight sectors; superior, superonasal, nasal, inferonasal, inferior, inferotemporal, temporal, superotemporal along the scan (Fig. 2). The centers of two ETDRS grids, as existent at the provided software, were overlapped on the geometric center of the optic disc then manually rotated 90 degrees away from each other, such that each peripapillary ChT measurement is made 45 degrees away from one another (Fig. 2). Central macular thickness (CMT), overall and the same eight sector peripapillary RNFL thickness values were also recorded for each participant.

All statistical analyses were performed using IBM SPSS Statistics for Windows, Version 22.0 (IBM Corp., Armonk, NY) and p $<0.05$ was considered statistically significant. Numerical values have been reported as mean \pm standard deviations (SD) or as median with minimums and maximums when necessary. The Shapiro-Wilk test was used as the test for normality. The t-test and Mann-Whitney U tests were used for two-group comparisons. Bivariate correlations were evaluated using Pearson correlation coefficient and Spearman's rank correlation coefficient.

\section{Results}

Two hundred and six eyes of 103 patients with T1D

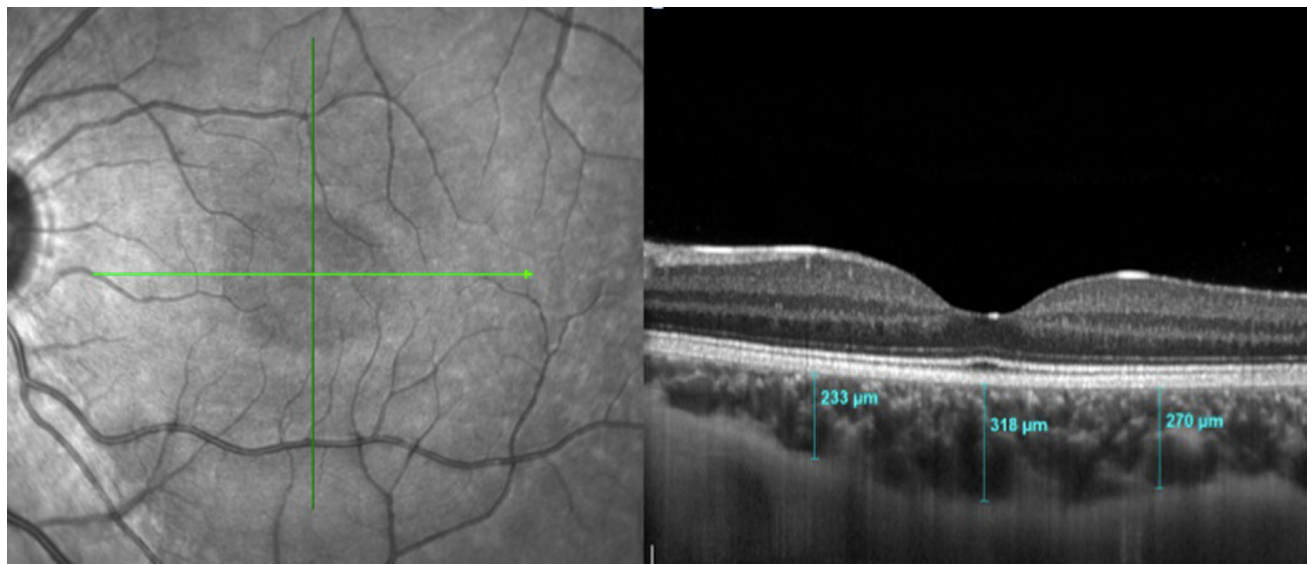

Fig. 1. Example of macular choroidal thickness measurements at three points. A standard macular scan with optical coherence tomography (OCT) (left) and horizontal high definition retinal images (right). The choroid is clearly visible underneath the retinal layers and manual choroidal thickness measurements are demonstrated at the subfoveal point as well as $1,500 \mu \mathrm{m}$ nasal to the fovea and 1,500 $\mu \mathrm{m}$ temporal to the fovea (right).

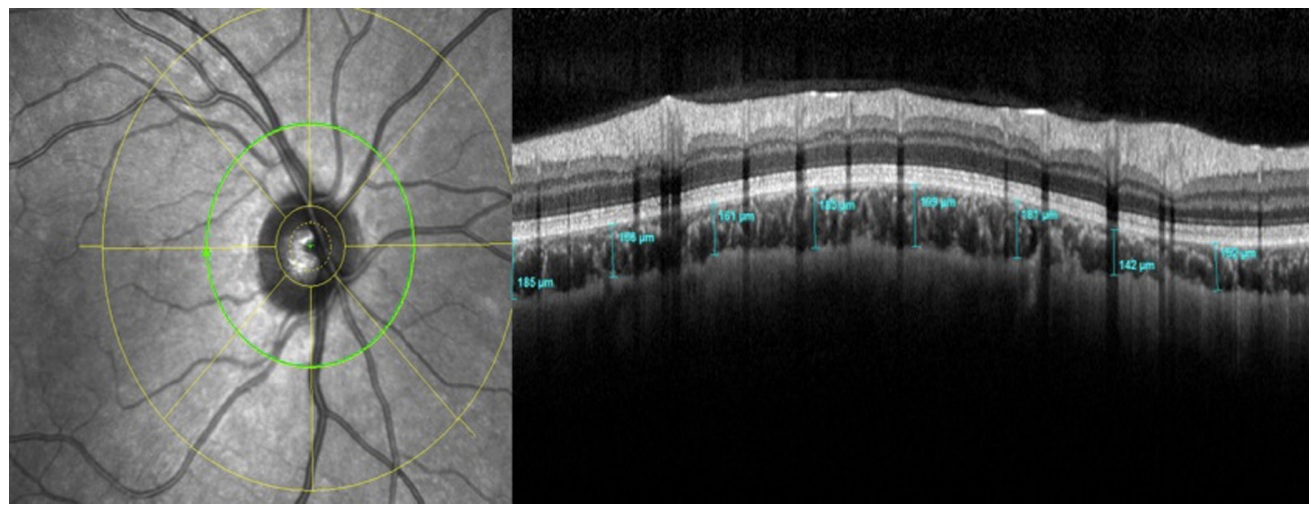

Fig. 2. Demonstration of peripapillary choroidal thickness measurements. A standard optic disc with optical coherence tomography (OCT) (left) and corresponding high definition retinal images (right). The centers of 2 Early Treatment Diabetic Retinopathy Study (ETDRS) grids, as existent in the provided software, were overlapped on the geometric center of the optic disc then manually rotated 90 degrees away from each other such that each peripapillary choroidal thickness measurement is made with 45 degrees away from one another (right). 
who met the inclusion criteria were enrolled in this study. Eighty-eight eyes of 44 age-matched healthy children served as controls. No significant difference was observed among the two groups in terms of age $(y r)(p=0.364)$, $\operatorname{IOP}(\mathrm{mmHg})(\mathrm{p}=0.072)$, and AL $(\mathrm{mm})(\mathrm{p}=0.081)$ values. The mean duration of T1D was $5.17 \pm 3.07 \mathrm{yr}$ (range $1-14$ ), and the mean HbA1c was $9.57 \pm 1.98 \%$ (range 5.6-14.8). The demographic and clinical characteristics of the subjects (eyes) are shown in Table 1.

Eyes with T1D had a mean subfoveal ChT (SFChT) of $311.75 \pm 41.97 \mu \mathrm{m}$, and in healthy subjects the mean SFChT was $312.65 \pm 63.76 \mu \mathrm{m}(p=0.835)$ (Table 2). Furthermore, there were no statistically significant differences between the macular ChT measurements of the nasal and temporal macula of both groups ( $p=$
0.305, $\mathrm{p}=0.054)$. Table 3 shows the peripapillary ChT measurements between diabetic eyes and controls at the eight examined points. All detected values were thinner throughout the T1D group; however, the difference was statistically significant in the superonasal, nasal, inferonasal and inferior sectors only $(p=0.010, p=0.020$, $\mathrm{p}=0.019$, and $\mathrm{p}=0.018$, respectively). In addition, $\mathrm{a}$ correlation analysis between macular and peripapillary ChT measurements and age, gender, disease duration and HbA1c levels was performed and no significant associations were noted between these variables ( $p>0.05)$.

Mean central macular retinal thickness was 255.37 $\pm 35.08 \mu \mathrm{m}$ in the control group versus $258.11 \pm 20.95$ $\mu \mathrm{m}$ in diabetics $(\mathrm{p}=0.742)$ (Table 2). Mean overall and eight sector RNFL thickness measurements were

Table 1. Demographic and clinical characteristic findings among the two groups

\begin{tabular}{lccc}
\hline & Type 1 diabetes & Controls & $P$ values \\
& n, eyes $=206$ & n, eyes $=88$ & \\
\hline Age (yr, mean \pm SD) & $13.09 \pm 2.93$ & $13.45 \pm 3.94$ & 0.364 \\
Gender (female/male) & $86 / 120$ & $66 / 22$ & 0.001 \\
BCVA & $0.97 \pm 0.07$ & $1.00 \pm 0.00$ & - \\
Spherical equivalent refractive error (diopters, mean \pm SD) & $-0.15 \pm 1.02$ & $-0.56 \pm 0.99$ & 0.001 \\
IOP (mmHg) & $13.90 \pm 1.59$ & $13.27 \pm 1.74$ & 0.072 \\
Axial length (mm) & $23.14 \pm 0.83$ & $22.35 \pm 1.97$ & 0.081 \\
Disease duration (yr, mean \pm SD) & $5.17 \pm 3.07$ & - & - \\
HbA1c (\%) & $9.57 \pm 1.98$ & - & - \\
\hline
\end{tabular}

BCVA, Best corrected visual acuity; IOP, Intraocular pressure; HbA1c, Hemoglobin A1c; SD, Standard deviation.

Table 2. Comparison of central macular thickness and macular choroidal thickness values among groups

\begin{tabular}{|c|c|c|c|c|c|}
\hline \multirow{2}{*}{$(\mu \mathrm{m})$} & \multicolumn{2}{|c|}{$\begin{array}{l}\text { Type } 1 \text { diabetes } \\
\text { n, eyes }=206\end{array}$} & \multicolumn{2}{|c|}{$\begin{array}{c}\text { Controls } \\
\mathrm{n} \text {, eyes }=88\end{array}$} & \multirow{2}{*}{$P$ values } \\
\hline & Mean \pm SD & $\begin{array}{c}\text { Median } \\
(\min -\max )\end{array}$ & Mean \pm SD & $\begin{array}{c}\text { Median } \\
(\min -\max )\end{array}$ & \\
\hline Central macular thickness & $258.11 \pm 20.95$ & $255(221-380)$ & $255.37 \pm 35.08$ & $260(119-332)$ & 0.742 \\
\hline Sub-Foveal choroidal thickness & $311.75 \pm 41.97$ & $319.5(177-407)$ & $312.65 \pm 63.76$ & $315(189-453)$ & 0.835 \\
\hline Nasal choroidal thickness & $246.96 \pm 41.66$ & $252.5(127-347)$ & $254.0 \pm 56.83$ & $248(147-419)$ & 0.305 \\
\hline Temporal choroidal thickness & $281.38 \pm 41.01$ & $284(163-398)$ & $295.14 \pm 59.15$ & $300(148-447)$ & 0.054 \\
\hline
\end{tabular}

SD: Standard deviation.

Table 3. Peripapillary choroidal thickness values among the two groups

\begin{tabular}{|c|c|c|c|c|c|}
\hline \multirow{2}{*}{$(\mu \mathrm{m})$} & \multicolumn{2}{|c|}{$\begin{array}{c}\text { Type } 1 \text { diabetes } \\
\text { n, eyes }=206\end{array}$} & \multicolumn{2}{|c|}{$\begin{array}{c}\text { Controls } \\
\mathrm{n} \text {, eyes }=88\end{array}$} & \multirow{2}{*}{$P$ values } \\
\hline & Mean \pm SD & $\begin{array}{c}\text { Median } \\
(\min -\max )\end{array}$ & Mean $\pm \mathrm{SD}$ & $\begin{array}{c}\text { Median } \\
(\min -\max )\end{array}$ & \\
\hline Superior & $162.04 \pm 35.82$ & $160(55-263)$ & $171.89 \pm 42.33$ & $167(93-341)$ & 0.134 \\
\hline Superonasal & $159.34 \pm 36.17$ & $158(59-269)$ & $172.74 \pm 42.25$ & $170(93-305)$ & 0.010 \\
\hline Nasal & $161.84 \pm 36.13$ & $160(72-276)$ & $174.64 \pm 40.51$ & $175(96-300)$ & 0.020 \\
\hline Inferionasal & $155.84 \pm 35.75$ & $150(53-294)$ & $169.14 \pm 45.76$ & $166.5(90-320)$ & 0.019 \\
\hline Inferior & $142.70 \pm 32.43$ & $139(59-271)$ & $155.27 \pm 43.37$ & $151.5(68-289)$ & 0.018 \\
\hline Inferotemporal & $157.97 \pm 33.18$ & $155(65-272)$ & $166.51 \pm 41.48$ & $163.5(93-292)$ & 0.182 \\
\hline Temporal & $167.03 \pm 35.73$ & $164(65-279)$ & $177.34 \pm 46.51$ & $173(96-308)$ & 0.200 \\
\hline Superotemporal & $165.16 \pm 34.46$ & $163(72-287)$ & $173.87 \pm 42.89$ & $170(99-297)$ & 0.236 \\
\hline
\end{tabular}

SD: Standard deviation. 
slightly thinner in the T1D group; nevertheless, only the temporal sector value was statistically significant $(p=0.032)($ Table 4).

\section{Discussion}

Loss of visual function in T1D remains a significant global health problem. Detection of early alternations prior to the morphologic changes could be of crucial importance by providing a means to prevent the consequences of vascular damage and subsequent blindness related to retinopathy complications. In the light of this data, our study aimed to investigate choroidal and retinal alternations during $\mathrm{T} 1 \mathrm{D}$ in pediatric patients with no signs of diabetic retinopathy. To the best of our knowledge, this is also the first study to evaluate peripapillary changes in pediatric patients with T1D using EDI-OCT technology.

Currently, the retinal neurodegenerative process is considered to precede clinically detected microvascular changes in the course of diabetic eye disease $(3,4)$. Mounting evidence suggests a stepwise involvement of selective loss of ganglion cell layer followed by RNFL before visible vascular signs occur (13-15). Therefore, several groups previously investigated RNFL thickness changes in diabetic eyes with and without retinopathy to determine if OCT imagining would be an adequate choice of scanning option for these patients (13-19). Studies focused on adult patients with T1D demonstrated selective thinning of RNFL during the early stages of DR, however the authors reported no difference between patients without DR and healthy controls (14, 17). Elhabashy and collaborators examined adolescent patients with $\mathrm{T} 1 \mathrm{D}$ without retinopathy and demonstrated that superior and inferior RNFL thickness measurements show no significant difference in comparison to that of healthy individuals (18). A more recent study, however, speculated that the mean average RNFL and ganglion cell complex thicknesses in diabetics with no DR were significantly lower than that of controls (19). One consideration to these contradictory results may be that the latter study included patients with $\mathrm{T} 1 \mathrm{D}$ with a duration of at least five years thus giving more time for the possibility of progression of the neurodegenerative changes. The mean disease duration in our study was $5.17 \pm 3.07 \mathrm{yr}$ and the results showed no significant differences in the overall RNFL thickness values between the diabetic eyes without retinopathy $(101.29 \pm 8.56 \mu \mathrm{m})$ and that of healthy controls $(102.16 \pm 14.32 \mu \mathrm{m})(\mathrm{p}>0.05)$. Although eight sector RNFL thickness measurements were slightly thinner in the T1D group, only the temporal sector value had statistical significance $(p=0.032)$.

The choroid, being a very vascular structure, is the main supply of blood, nutrients and growth factors to the outer retinal layers (20). The exact mechanism of choroidal thinning in variable stages of DR remains unknown. Due to diminished blood flow and increased vascular resistance leading to hypoxia, areas with thinner choroid might be more susceptible to retinal and choroidal diseases $(21,22)$. Adult patients with T1D without clinical signs of retinopathy were shown to have thinner foveal ChT compared to healthy subjects (23, 24). Conversely, previous reports on diabetic children observed no significant foveal ChT differences in comparison to control groups $(25,26)$. Our results are consistent with the previous literature showing no significant difference with regards to foveal ChT. On the other hand, studies investigating peripapillary choroidal alternations in diabetic eyes are still limited. Vujosevic et al. showed a significant decrease in peripapillary ChT with the increase of severity in diabetic retinopathy and no difference between healthy adult subjects and diabetic eyes without signs of retinopathy (20). Our data demonstrated thinner peripapillary ChT measurements in pediatric diabetic eyes with statistically significant differences at the superonasal, nasal, inferonasal, and inferior sectors $(p=0.010, p=0.020, p=0.019$, and $p=$ 0.018 , respectively). The peripapillary choroid is known to nourish the preliminary and retrolaminary portions of the optic disc (27). The clinical importance of choroidal changes in this specific population remains uncertain; however, we believe that a thinner peripapillary choroid might result in the optic disc being more vulnerable to changes in the choroidal circulation and hypoxia related

Table 4. Comparison of retinal nerve fiber layer (RNFL) thickness values among the two groups

\begin{tabular}{|c|c|c|c|c|c|}
\hline \multirow{2}{*}{$(\mu \mathrm{m})$} & \multicolumn{2}{|c|}{$\begin{array}{l}\text { Type } 1 \text { diabetes } \\
\text { n, eyes }=206\end{array}$} & \multicolumn{2}{|c|}{$\begin{array}{c}\text { Controls } \\
\mathrm{n} \text {, eyes }=88\end{array}$} & \multirow{2}{*}{$P$ values } \\
\hline & Mean \pm SD & $\begin{array}{c}\text { Median } \\
(\min -\max )\end{array}$ & Mean \pm SD & $\begin{array}{l}\text { Median } \\
\text { (min-max) }\end{array}$ & \\
\hline Overall RNFL & $101.29 \pm 8.56$ & $101(78-136)$ & $102.16 \pm 14.32$ & $103(61-126)$ & 0.174 \\
\hline Superior & $131.28 \pm 15.77$ & $132(91-200)$ & $131.87 \pm 17.72$ & $131(94-185)$ & 0.990 \\
\hline Superonasal & $118.96 \pm 21.89$ & $120(63-188)$ & $119.20 \pm 23.11$ & $119(72-194)$ & 0.844 \\
\hline Nasal & $72.84 \pm 13.40$ & $72(36-117)$ & $76.13 \pm 14.93$ & $75.5(41-122)$ & 0.062 \\
\hline Inferionasal & $108.74 \pm 22.14$ & $108(56-182)$ & $108.84 \pm 23.05$ & $106(61-164)$ & 0.973 \\
\hline Inferior & $128.06 \pm 14.64$ & $128.5(91-178)$ & $129.91 \pm 16.25$ & $129(87-171)$ & 0.338 \\
\hline Inferotemporal & $146.75 \pm 18.62$ & $145(87-208)$ & $150.42 \pm 17.82$ & $151.5(85-192)$ & 0.118 \\
\hline Temporal & $73.11 \pm 11.08$ & $72(44-104)$ & $76.44 \pm 14.45$ & $76(40-108)$ & 0.032 \\
\hline Superotemporal & $143.48 \pm 19.06$ & $145(87-211)$ & $144.94 \pm 18.09$ & $146.5(95-199)$ & 0.819 \\
\hline
\end{tabular}


damage with subsequent vision loss. This theory was further supported by a study on glaucomatous eyes when visual field defects were found to progress faster in corresponding optic nerve damage areas (22). The present study also demonstrated that the peripapillary choroid was thinnest inferiorly compared to other sectors in both diabetics and controls. These results comply with previously published data on healthy pediatric subjects $(28,29)$. It is still not clearly established why the inferior portion is thinner versus all other peripapillary quadrants. However, this may be explained with regards to the embryological aspect that the optic fissure is the last part to close and it is closed inferiorly to the optic cup where the optic disk originates (30). In this study, we did not observe a correlation between macular and peripapillary ChT measurements with age, gender, disease duration, and HbA1c levels ( $p>0.05)$. Similarly, Sayin et al. and Gołębiewska et al. showed in their studies that macular ChT in pediatric diabetic eyes were not affected by the patient age, duration of diabetes, or HbA1c levels $(25,26)$. On the contrary, Niestrata-Ortiz et al. demonstrated a positive correlation between the disease duration and foveal $\mathrm{ChT}$ in pediatric patients with T1D without DR (31). Interestingly, this study also revealed increased foveal ChT with no change in retinal thickness in their study group in comparison to age-matched controls. The authors associated the thickening of the choroid with choroidal swelling secondary to diabetes and hypothesized that vascular pathological changes develop from the outermost choroid towards the retina prior to development of DR (31). Finally, the results of choroidal thickness changes in diabetic patients without retinopathy vary in the current literature. However, all evidence suggests a degree of change within the structure of the choroid along the vascular process of diabetic retinopathy.

Our study is not without limitations. First, the sample size used in the present study was relatively small. There was a statistical difference by means of peripapillary choroidal thickness between the diabetic eyes and the controls, but this small difference may not permit the discrimination of possible clinical outcomes on an individual patient basis. Second, patients with chronic diseases such as systemic hypertension, renal dysfunction, hyperlipidemia, obesity and autoimmune thyroiditis were excluded to minimize vascular alternations. Therefore, the effects of such co-morbidities on choroidal alterations were not assessed due to the homogeneity of our study group. Bulus et al. previously showed a positive correlation between subfoveal ChT and body mass index (BMI) in pediatric population (32). Although BMI values were not recorded at the time of testing in this study, we do not estimate any reflection on the results given that all patients were monitored closely by our institution's Pediatric Endocrinology Department for any coexisting conditions and those with obesity were strictly excluded. Third, it remains uncertain if gender has an influence on choroidal thickness and results in pediatric population vary between studies. In healthy children, Zhang et al. reported increased subfoveal ChT with male gender and Chiara et al. with females; whereas, other studies concluded no associations between gender and ChT changes (33-36). In children with T1D, Gołębiewska et al. showed a correlation between increased macular ChT and gender in favor of girls; however, other studies lack results on associations between gender and ChT $(25,26,31)$. Our study did not observe a relationship between gender and macular or peripapillary ChT values. Finally, a prospective design would more clearly reveal the role of choroidal circulation in the course of diabetic retinopathy. Further research with longer follow-up periods is needed to confirm the associated factors related to choroidal thickness and its effect on visual changes in this specific group of children.

In conclusion, our study demonstrated evidence that peripapillary choroidal thinning can be identified by EDI-OCT assessment in pediatric diabetic patients without visible signs of retinopathy. Recent advances in this non-invasive and fast technology provides us a detailed in-vivo evaluation of choroidal changes and displays retinal structural abnormalities in diabetic eyes. The detection of early vascular and neurodegenerative parameter changes in pediatric eyes with T1D suggests the usefulness of OCT as a diagnostic screening option. Although it is very early to claim OCT imaging as a solo retinopathy screening method in the pediatric T1D population, this tool yet proves to play a significant role in the assessment of this specific group where early detection of disease is highly valued and could be used as an adjunct to fundus examination.

Conflict of Interests: None of the authors have conflicts of interest to disclose regarding this manuscript.

\section{References}

1. Daneman D. Type 1 diabetes. Lancet 2006;367: 847-58. [Medline] [CrossRef]

2. Downie E, Craig ME, Hing S, Cusumano J, Chan AK, Donaghue KC. Continued reduction in the prevalence of retinopathy in adolescents with type 1 diabetes: role of insulin therapy and glycemic control. Diabetes Care 2011;34: 2368-73. [Medline] [CrossRef]

3. Barber AJ. A new view of diabetic retinopathy: a neurodegenerative disease of the eye. Prog Neuropsychopharmacol Biol Psychiatry 2003;27: 283-90. [Medline]

4. Antonetti DA, Klein R, Gardner TW. Diabetic retinopathy. N Engl J Med 2012;366: 1227-39. [Medline]

5. Barber AJ, Gardner TW, Abcouwer SF. The significance of vascular and neural apoptosis to the pathology of diabetic 
retinopathy. Invest Ophthalmol Vis Sci 2011;52: 1156-63. [Medline]

6. van Dijk HW, Kok PH, Garvin M, Sonka M, Devries JH, Michels RP, et al. Selective loss of inner retinal layer thickness in type 1 diabetic patients with minimal diabetic retinopathy. Invest Ophthalmol Vis Sci 2009;50: 3404-9. [Medline] [CrossRef]

7. Nickla DL, Wallman J. The multifunctional choroid. Prog Retin Eye Res 2010;29: 144-68. [Medline]

8. Fryczkowski AW, Sato SE, Hodes BL. Changes in the diabetic choroidal vasculature: scanning electron microscopy findings. Ann Ophthalmol 1988;20: 299-305. [Medline]

9. Fukushima I, McLeod DS, Lutty GA. Intrachoroidal microvascular abnormality: a previously unrecognized form of choroidal neovascularization. Am J Ophthalmol 1997;124: 473-87. [Medline] [CrossRef]

10. Cao J, McLeod S, Merges CA, Lutty GA. Choriocapillaris degeneration and related pathologic changes in human diabetic eyes. Arch Ophthalmol 1998;116: 589-97. [Medline] [CrossRef]

11. Manjunath V, Papastavrou V, Steel DH, Menon G, Taylor R, Peto T, et al. Wide-field imaging and OCT vs clinical evaluation of patients referred from diabetic retinopathy screening. Eye (Lond) 2015;29: 416-23. [Medline] [CrossRef]

12. Kim J, Brown W, Maher JR, Levinson H, Wax A. Functional optical coherence tomography: principles and progress. Phys Med Biol 2015;60: R211-37. [Medline] [CrossRef]

13. Chhablani J, Sharma A, Goud A, Peguda HK, Rao HL, Begum VU, et al. Neurodegeneration in type 2 diabetes: evidence from spectral-domain optical coherence tomography. Invest Ophthalmol Vis Sci 2015;56: 6333-8. [Medline] [CrossRef]

14. van Dijk HW, Verbraak FD, Kok PH, Garvin MK, Sonka M, Lee K, et al. Decreased retinal ganglion cell layer thickness in patients with type 1 diabetes. Invest Ophthalmol Vis Sci 2010;51:3660-5. [Medline] [CrossRef]

15. Carbonell M, Alonso N, Castelblanco E, Real J, Ramírez-Morros A, Simó R, et al. Assessment of inner retinal layers and choroidal thickness in type 1 diabetes mellitus: a cross-sectional study. J Clin Med 2019;8: 1412. [Medline] [CrossRef]

16. van Dijk HW, Verbraak FD, Kok PH, Stehouwer M, Garvin MK, Sonka M, et al. Early neurodegeneration in the retina of type 2 diabetic patients. Invest Ophthalmol Vis Sci 2012;53: 2715-9. [Medline] [CrossRef]

17. Gonul S, Ozkagnici A, Ozturk B, Kerimoglu H, Sahin A. Evaluation of retinal nerve fiber layer thickness with optical coherence tomography in type 1 diabetes mellitus patients. Turkiye Klinikleri J Med Sci. 2011;31: 1100-5. [CrossRef]

18. Elhabashy SA, Elbarbary NS, Nageb KM, Mohammed MM. Can optical coherence tomography predict early retinal microvascular pathology in type 1 diabetic adolescents without minimal diabetic retinopathy? A single-centre study. J Pediatr Endocrinol Metab 2015;28: 139-46. [Medline] [CrossRef]

19. El-Fayoumi D, Badr Eldine NM, Esmael AF, Ghalwash D, Soliman HM. Retinal nerve fiber layer and ganglion cell complex thicknesses are reduced in children with type 1 diabetes with no evidence of vascular retinopathy. Invest Ophthalmol Vis Sci 2016;57: 5355-60. [Medline] [CrossRef]

20. Vujosevic S, Martini F, Cavarzeran F, Pilotto E, Midena E. Macular and peripapillary choroidal thickness in diabetic patients. Retina 2012;32: 1781-90. [Medline] [CrossRef]

21. Tanabe H, Ito Y, Terasaki H. Choroid is thinner in inferior region of optic disks of normal eyes. Retina 2012;32: 134-9. [Medline] [CrossRef]

22. De Moraes CG, Prata TS, Tello C, Ritch R, Liebmann JM. Glaucoma with early visual field loss affecting both hemifields and the risk of disease progression. Arch Ophthalmol 2009;127: 1129-34. [Medline] [CrossRef]

23. Esmaeelpour M, Brunner S, Ansari-Shahrezaei S, Nemetz S, Považay B, Kajic V, et al. Choroidal thinning in diabetes type 1 detected by 3-dimensional $1060 \mathrm{~nm}$ optical coherence tomography. Invest Ophthalmol Vis Sci 2012;53: 6803-9. [Medline] [CrossRef]

24. Yolcu U, Çağıltay E, Toyran S, Akay F, Uzun S, Gundogan FC. Choroidal and macular thickness changes in type 1 diabetes mellitus patients without diabetic retinopathy. Postgrad Med 2016;128: 755-60. [Medline] [CrossRef]

25. Sayin N, Kara N, Pirhan D, Vural A, Ersan HB, Onal H, et al. Evaluation of subfoveal choroidal thickness in children with type 1 diabetes mellitus: an EDI-OCT study. Semin Ophthalmol 2014;29: 27-31. [Medline] [CrossRef]

26. Gołębiewska J, Olechowski A, Wysocka-Mincewicz M, Baszyńska-Wilk M, Groszek A, Czeszyk-Piotrowicz A, et al. Choroidal thickness and ganglion cell complex in pubescent children with type 1 diabetes without diabetic retinopathy analyzed by spectral domain optical coherence tomography. J Diabetes Res 2018;2018: 5458015. [Medline] [CrossRef]

27. Hayreh SS. The blood supply of the optic nerve head and the evaluation of it - myth and reality. Prog Retin Eye Res 2001;20: 563-93. [Medline] [CrossRef]

28. Wu XS, Shen LJ, Chen RR, Lyu Z. Peripapillary choroidal thickness in Chinese children using enhanced depth imaging optical coherence tomography. Int J Ophthalmol 2016;9: 1451-6. [Medline]

29. Read SA, Alonso-Caneiro D, Vincent SJ, Collins MJ. Peripapillary choroidal thickness in childhood. Exp Eye Res 2015;135: 164-73. [Medline] [CrossRef]

30. Schoenwolf GC, Bleyl SB, Brauer PR, Francis-West PH. Larsen's Human Embryology. Philadelphia, PA: Elsevier. 2009; $602-16$.

31. Niestrata-Ortiz M, Fichna P, Stankiewicz W, Stopa M. Determining the effect of diabetes duration on retinal and choroidal thicknesses in children with type 1 diabetes mellitus. Retina 2020;40: 421-7. [Medline] [CrossRef]

32. Bulus AD, Can ME, Baytaroglu A, Can GD, Cakmak HB, Andiran N. Choroidal thickness in childhood obesity. Ophthalmic Surg Lasers Imaging Retina 2017;48: 10-7. [Medline] [CrossRef]

33. Zhang JM, Wu JF, Chen JH, Wang L, Lu TL, Sun W, et al. Macular choroidal thickness in children: The Shandong children eye study. Invest Ophthalmol Vis Sci 2015;56: 7646-52. [Medline] [CrossRef]

34. Mapelli C, Dell'Arti L, Barteselli G, Osnaghi S, Tabacchi E, Clerici M, et al. Choroidal volume variations during childhood. Invest Ophthalmol Vis Sci 2013;54: 6841-5. [Medline] [CrossRef]

35. Read SA, Collins MJ, Vincent SJ, Alonso-Caneiro D. Choroidal thickness in childhood. Invest Ophthalmol Vis Sci 2013;54: 3586-93. [Medline] [CrossRef]

36. Park KA, Oh SY. Choroidal thickness in healthy children. Retina 2013;33: 1971-6. [Medline] [CrossRef] 